\title{
Abundance and Distribution of the Hyponeustonic Copepods Anomalocera patersonii and Pontella mediterranea in the South-western Part of the Black Sea
}

\section{George-Emanuel Harcotă ${ }^{1,2, *}$ (D) Aurelia Țotoiu ${ }^{1}$, Elena Bișinicu ${ }^{1}$, Cristina Tabarcea ${ }^{1}$, Laura Boicenco $^{1}$, Florin Timofte ${ }^{1}$}

\author{
${ }^{1}$ National Institute for Marine Research and Development “Grigore Antipa”, 300 Mamaia Blvd, 900581, Constanta, \\ Romania \\ ${ }^{2}$ University of Bucharest, Doctoral School of Ecology, Bucharest \\ How to cite
}

Harcotă, G.E., Țotoiu, A., Bişinicu, E., Tabarcea, C., Boicenco, L., Timofte, F. (2022). Abundance and Distribution of the Hyponeustonic Copepods Anomalocera patersonii and Pontella mediterranea in the South-western Part of the Black Sea. Turkish Journal of Fisheries and Aquatic Sciences, 22(5), TRJFAS18987. http://doi.org/10.4194/TRJFAS18987

\section{Article History}

Received 21 January 2021

Accepted 10 December 2021

First Online 21 December 2021

\section{Corresponding Author}

E-mail: gharcota@alpha.rmri.ro

\author{
Keywords \\ Density \\ Development Stages \\ Qualitative \\ Quantitative
}

\begin{abstract}
The paper presents the analysis of hyponeustonic species present in the south-western part of the Black Sea, in October 2019, within the ANEMONE Project. From the qualitative and quantitative point of view, two species were identified: Anomalocera patersonii Templeton, 1837 (WoRMS) and Pontella mediterranea Claus, 1863 (WoRMS). The analyzed samples showed significant densities of these species, being found in different development stages, from nauplii to copepodites but also as adults and having a representative distribution on the entire analyzed surface. A. patersonii was abundant in the northern part of the Romanian marine area, the southern marine area of Bulgaria and in Turkey central area, while $P$. mediterranea recorded a higher abundance in the Romanian Black Sea area.
\end{abstract}

\section{Introduction}

At first, biologists believed that the rough surface of seas and oceans was not suitable for organisms adapted to life conditions in the pelagic zone. Marine biologists focused on the upper surface of the sea as a special ecosystem, significant discoveries being made. Organisms that have living forms close to the surface, at the interface of the atmosphere were considered to exist only in small ponds, lakes, pools protected from the wind (Zernov, 1934).

In areas with rivers influence, where sea water meets river waters forming a transitional water (hydro front), usually 1-2 m thick, but sometimes narrowing to as little as half a meter, the abundance of neuston organisms increases considerably (Zaitsev, 1970). There are usually two distinct categories within it: epineustonic organisms and hyponeustonic organisms.

Neustonic organisms are those that live in the surface layers of water bodies. The hyponeuston is composed of inhabitants of the $0-5 \mathrm{~cm}$ layer, conditionally considered as an aquatic neuston biotope (Zaitsev, 1968; 1971).

The trophic pyramid of neuston is essentially composed of bacteria, phytoneuston and animal hyponeuston. Organisms that spend their entire life cycle inside the neuston, found in the first centimeters of the water column, constitute the hyponeuston. Other organisms appear only during a part of the life cycle in the neustonic layer, constituting the temporary merohyponeuston or the temporary hyponeustone. The hyponeuston consists essentially of copepods of 
Pontellidae family (Pontella). Merohypononeuston consists of larval and juvenile forms of numerous planktonic taxa (Copepoda, Euphausiacea, Decapoda), benthic (Decapoda, Polychaeta, Mollusca, Echinodermata, Cirripedia) and planktonic larvae and larval stages of fish (Ré, 2005).

One of the most important issues in biodiversity is the concept of "critical biotopes", i.e., areas which are critical to the survival of certain species. If critical biotopes are subjected to pollution, contaminants such as heavy metals and various petroleum hydrocarbons which are frequently introduced in the surface layer (e.g., river run-off and oil spills by ships, oil platform) (Hardy, 1997; Wurl \& Obbard 2004), or other negative impacts, the result may be the diminution or even disappearance of entire populations of plants and animals (Zaitsev et al., 1997).

Neustonic organisms are also exposed to dramatic changes in salinity after heavy rainfall or evaporation and have to endure strong wave action during storms (Marshall \& Burchardi 2005). The composition of the (macro) neuston is highly variable and mainly depends on vertical migration (circadian rhythms), temporal and spatial variation (Rawlinson et al., 2005). The vertical distribution and migratory patterns of fauna are influenced by the light/dark cyclic periods perceived below the surface and the wavelengths visible at various depths (Marshall \& Burchardi 2005). Especially UVradiation and increased visibility to predators prevent most species from living the sea surface during the day (Holdway \& Maddock 1983).

The high amount of stress induced by biotic and abiotic factors gives rise to a number of adaptation strategies in neustonic organisms (Tully \& O'Ceidigh 1989). The part of pleustonic organisms (e.g. Velella, Physalia) that projects above the water, for example, can withstand prolonged desiccation and exposure to direct solar irradiation (Zaitsev, 1970; 1990). Moreover, neustonic organisms often have a specific pigmentation, with a blue color on the upper side and a silvery color on the lower side of the body, which can screen solar radiation and reduce predation (Doyle, 1992).

This paper aims to highlight the composition and distribution of hyponeuston in the southwestern part of the Black Sea, the method in which the organisms were sampled and analyzed.

The low density of the organisms can be influenced by environmental conditions, pollution, meaning that the hyponeuston is exposed to all kinds of biological, physical and chemical factors. The most important factors are the physical ones, the extreme waves hindering the organisms from reaching the surface layer, leading even to mortalities in the population.

One of the copepod's adaptation is their capacity of changing the color, having the possibility to merge with the environment. Therefore, the species color varies from blue to green, depending on the sea color which changes according to the marine areas, from the central regions to the coastal and even to the freshwater areas.

\section{Materials and Methods}

Between 30.09.2019 - 08.10.2019, an international expedition (ANEMONE joint cruise) took place on the continental shelf of the Black Sea (Romania, Bulgaria, Turkey) in which 19 hyponeuston samples were collected in marine waters of: Romania (6), Bulgaria (7), and Turkey (6) (Figure 1).

\section{Collection method}

A net for neuston sampling was used to collect hyponeuston samples. The used equipment was manufactured by Hydro-Bio, with a frame of $70 \times 40 \mathrm{~cm}$, a net bag of $260 \mathrm{~cm}$ length and a mesh of $200 \mu \mathrm{m}$, with floats mounted on the sides of the frame to support the net on the water surface. These characteristics of the neustonic net allow the accumulation of organisms and particles that flow on the sea surface layer.

After assembling the net, it was attached to the winch cable and rinsed with fresh water before use to prevent sample contamination.

After the research vessel reached a constant speed of $2 \mathrm{~m} / \mathrm{s}$, the neustonic net was launched from the vessel's starboard side, using the crane equipped with winches (Figure 2).

After the net was launched, the following were noted:

Sampling start time.

The starting value of the flowmeter.

Start GPS position.

Average speed of the RV

While towing the net, the ship had a semicircular motion to prevent the net from entering the ship's operating area.

The sampling time was 10 minutes, after the time expired, the net was slowly towed on board the ship.

After the net was lifted out of the water the following were noted:

The end time of the sampling.

Flowmeters stop value.

End GPS position.

During the sampling, the net was introduced into the water only halfway, in order to take the organisms from the surface layer of the water.

The net is recommended to be washed with filtered seawater on the outside of the sieve to avoid possible contamination. After the sampling was performed, the collecting recipient was detached, and the sample was stored in $1 \mathrm{~L}$ container, preserved with 8 $\mathrm{mL}$ of $37 \%$ formaldehyde per $100 \mathrm{~mL}$ sample and stored in a sun-protected place.

After each sampling, the net and the flowmeter must be rinsed thoroughly with fresh water (Figure 3a, b). 


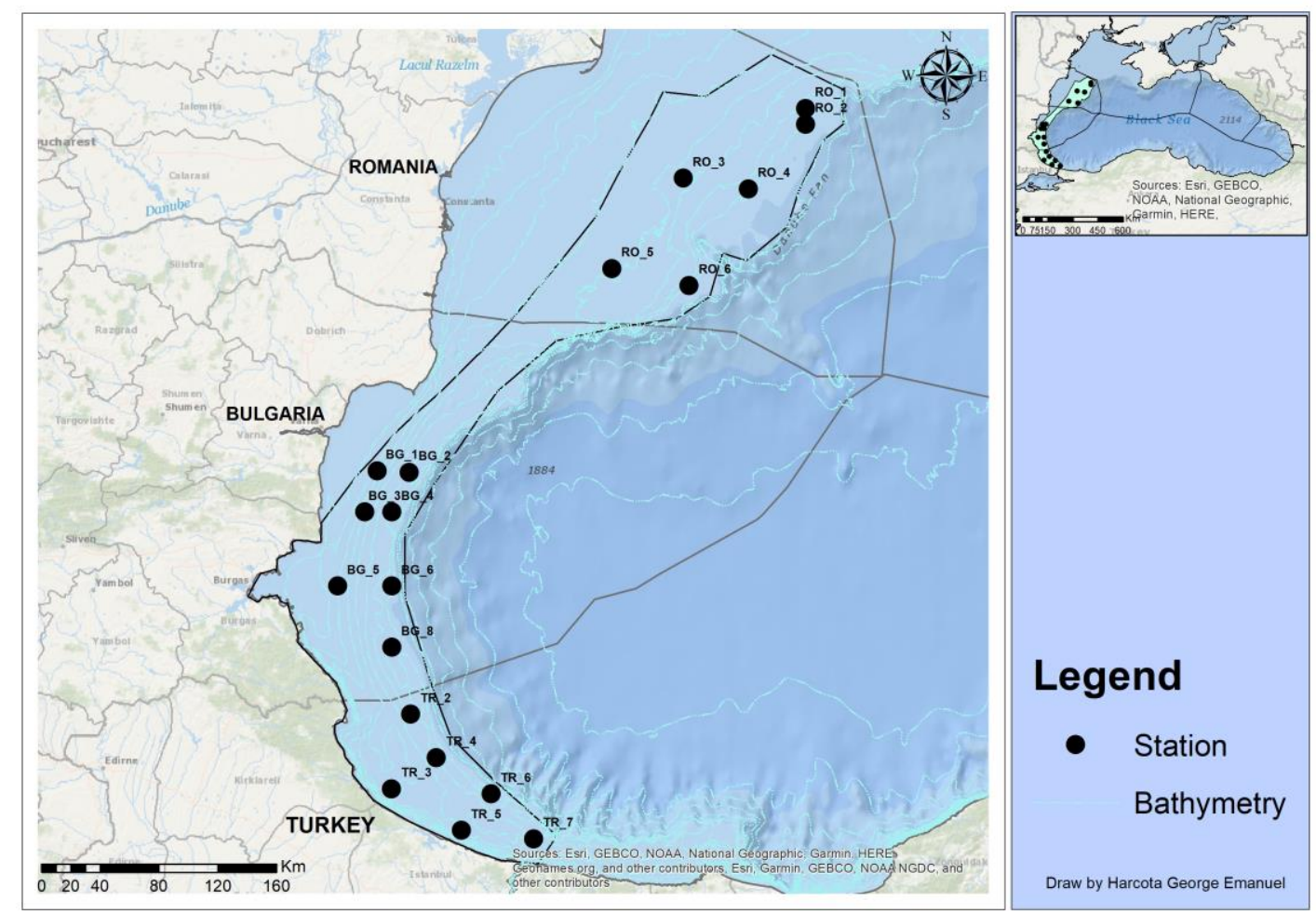

Figure 1. Map of sampling stations in the joint cruise.

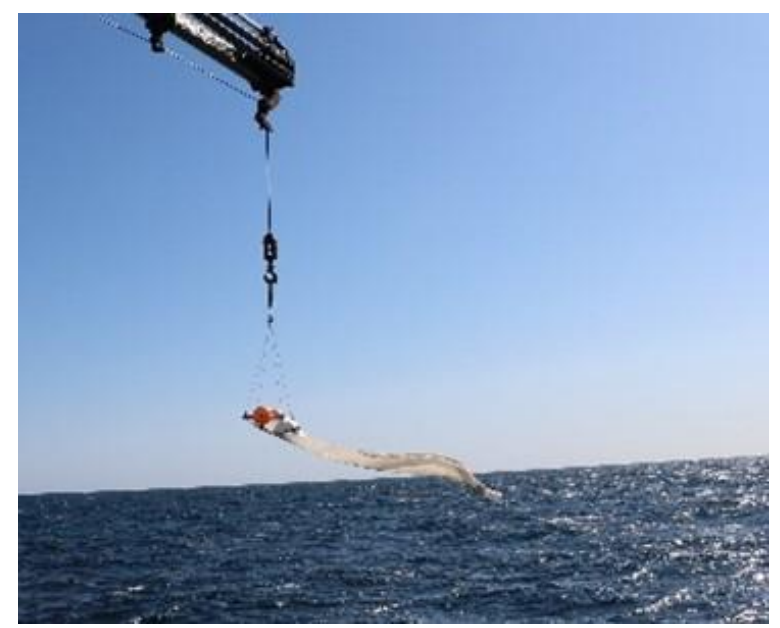

Figure 2. Sampling of hyponeuston (original photo)

The volume of filtered water is calculated using a flowmeter. Installation of the mechanical Flow Meter is made by triple point connection of the nose piece inside the net ring. The mechanical Flow Meter incorporates a three-blade impeller coupled directly to a five-digit counter which records each revolution of the impeller. The pitch of the impeller is $0.3 \mathrm{~m}$ per revolution, the number of revolutions multiplied with 0.3 . For quantitative measurements the threshold flow velocity of the impeller should not be smaller than $0.5 \mathrm{~m} / \mathrm{sec}$. For comparison measurements flow velocities smaller than $0.5 \mathrm{~m} / \mathrm{sec}$. The opening area of the Plankton Net must be known or must be calculated. The water volume passed through the Plankton Net is determined as follows: indicated number of revolutions $\times 0.3 \times$ net opening area $\left(\mathrm{m}^{2}\right) \times 1000=$ water volume makes the towing distance (https://www.hydrobios.de).

\section{Analysis method}

For microscopic processing, the sample was passed through a $60 \mu \mathrm{m}$ sieve, retaining the organisms (Figure $4 a, b)$.

The sample was washed with filtered seawater to minimize the amount of formaldehyde and it was reduced to a lower volume, depending on the sample density.

The number of individuals and mean individual weights were used for estimating the density as ind $/ \mathrm{m}^{3}$, respectively the biomass as $\mathrm{mg} / \mathrm{m}^{3}$ wet weight (Petipa, 


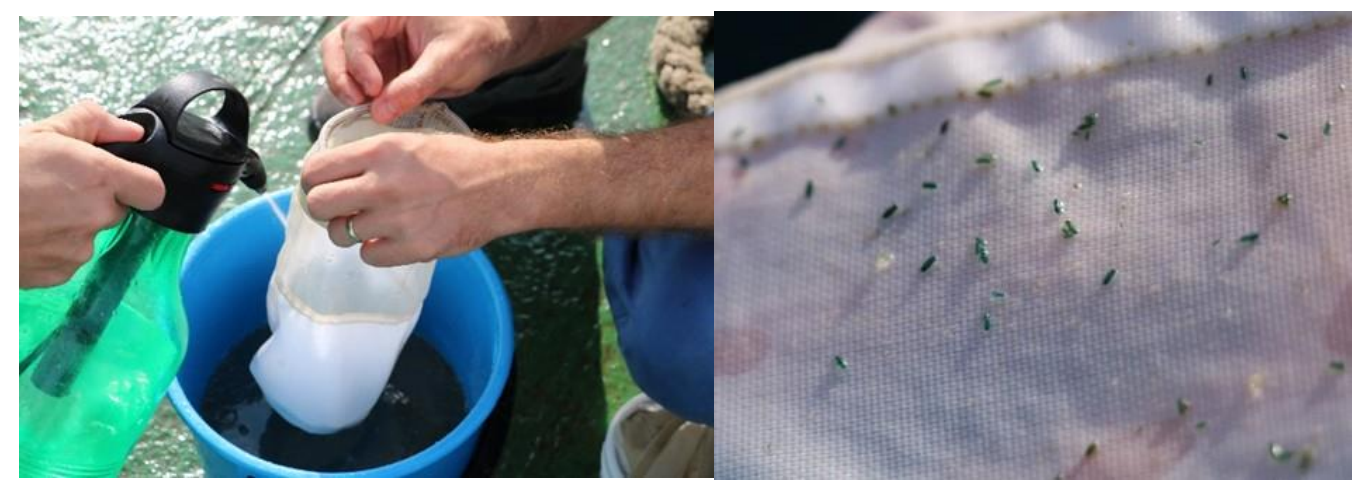

Figure 3a-b. Sampling of hyponeuston (original photo)

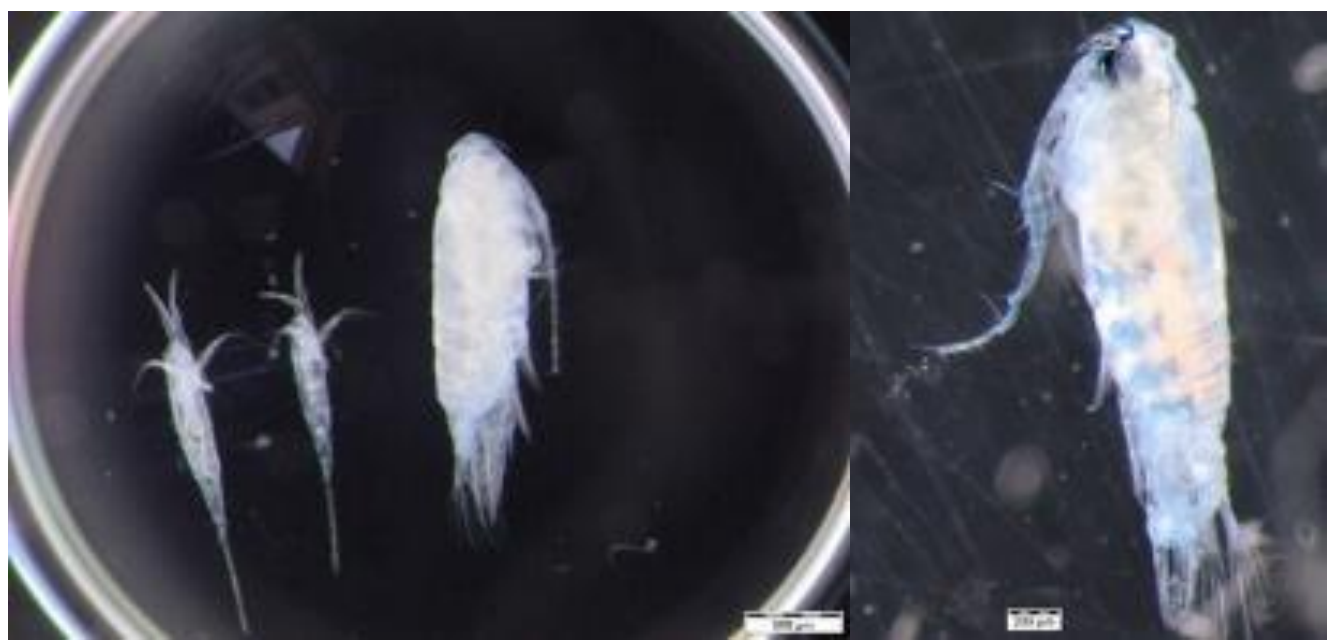

Figure 4 a, b. Pontellidae - identified in the samples (original photo)

1957) (Alexandrov et al., 2014). Determination of zooplankton biomass was based on the tables of constant weight of the Black Sea zooplankters. The biomass $\left(\mathrm{mg} / \mathrm{m}^{3}\right)$ calculations are based on the abundance values for counted taxa and developmental stages multiplied by the corresponding individual weight factors

The sample was homogenized, and quantitative and qualitative processing was performed in the Bogorov chamber/Petri dish, under Olympus SZX10.

\section{Statistical method}

In this paper we used graphs made in Excel, and the maps were made in the ArcGIS/ArcMap software. ArcMap is displaying and exploring GIS datasets for the study area, assigns symbols and creates map layouts for printing or publication. ArcMap is also the application used to create and edit datasets.

Description of organisms: $A$. patersonii. The head is somewhat triangular with a recurved spine or cephalic hook on each side. It bears two pairs of dorsal ocular lenses (Figure 5). There is a ventral eye and five obvious thoracic segments, the last of which is asymmetrical in the male. The antennule is about half the length of the body and has about twenty joints. It is of very uneven thickness in the male. The length of females is 3.5-4.2 $\mathrm{mm}$, of males 3-4 mm (GEF, 1999).

$P$. mediterranea (Figure 6). The shape of the head is triangular with side hooks, with a pair of dorsal ocular lenses on the head. Females have sizes ranging from 2.9 to $3.0 \mathrm{~mm}$, and males have smaller sizes from 2.75 to $2.85 \mathrm{~mm}$ (GEF, 1999).

Both species are of blue or blue green color and are found in all the Black Sea, except in low salinity areas and the Sea of Azov, Mediterranean Sea, Atlantic Ocean, English Channel, North Sea, Pacific Ocean.

\section{Results}

The analysed species inhabit the water's surface microlayer of $0-5 \mathrm{~cm}$, living in coastal and open sea areas, wintering dormant eggs which are laid on the bottom. Limiting factors are surface water pollution and the lack of oxygen in the near-bottom layer (GEF, 1999).

A. patersonii: In Romanian marine waters the highest value of density was recorded in station RO_1 (15.69 ind. $\left./ \mathrm{m}^{3}\right)$, the lowest value being recorded in station RO_3 (1.75 ind $/ \mathrm{m}^{3}$ ) (Figure $\left.7 ; 8\right)$.

In the Bulgarian marine waters, the highest density value appeared in station BG_8 $\left(11.17 \mathrm{ind} / \mathrm{m}^{3}\right)$, and the lowest in station BG_2 (1.42 ind $\left./ \mathrm{m}^{3}\right)$ (Figure $\left.7 ; 8\right)$. 


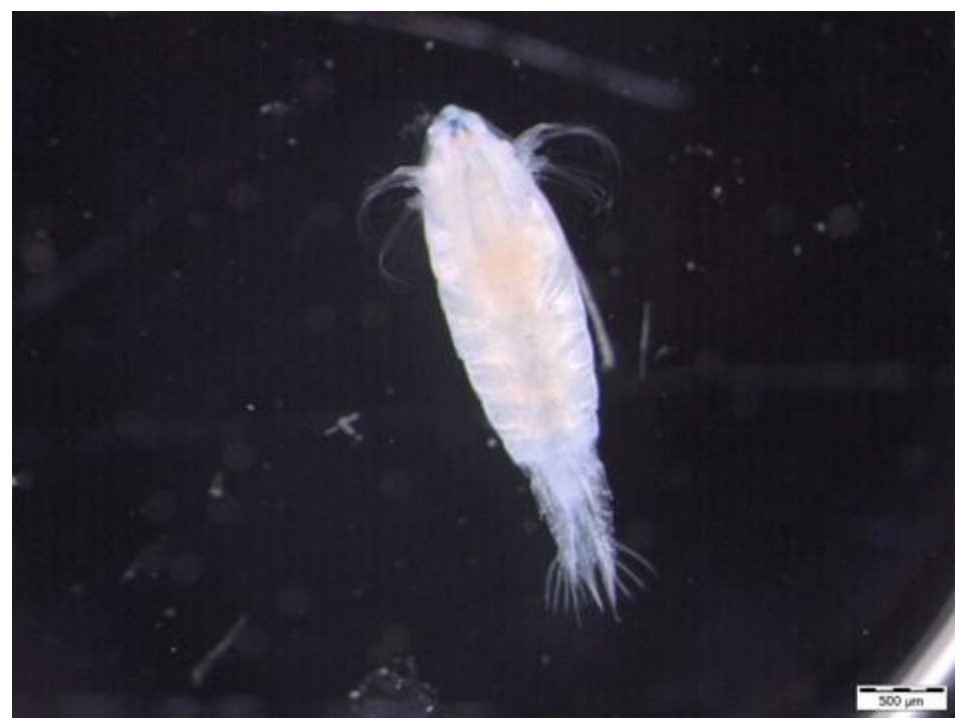

Figure 5. A. patersoni (original photo)

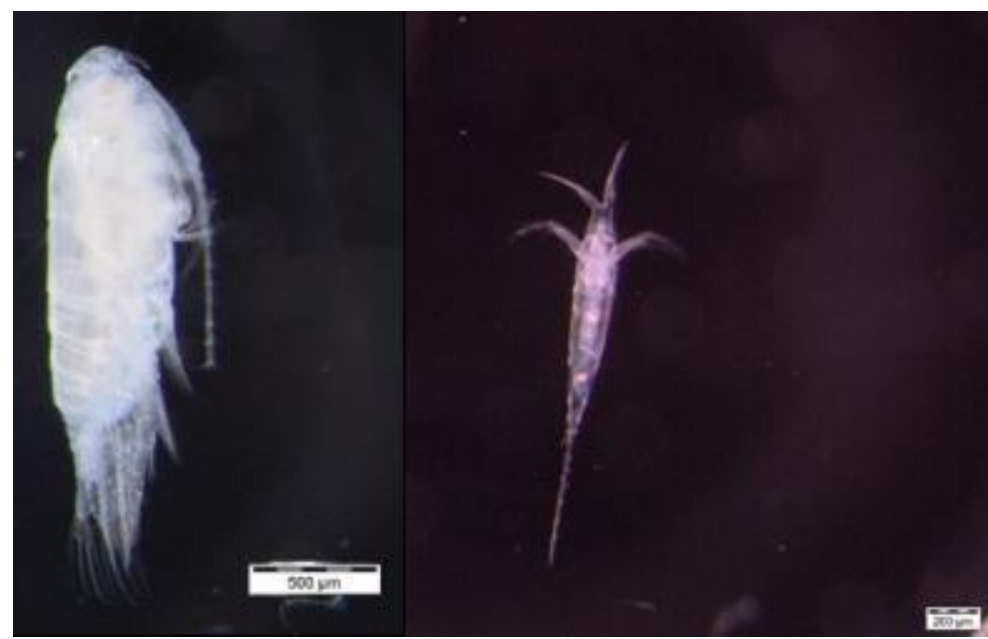

Figure 6. $P$. mediterranea (original photo)

The highest density value in the samples collected from the Turkish marine waters was registered in station TR_4 $\left(15.78 \mathrm{ind} / \mathrm{m}^{3}\right)$, and the lowest in station TR_7 $\left(1.64 \mathrm{ind} / \mathrm{m}^{3}\right.$ ) (Figure $\left.7 ; 8\right)$.

The average density values for this species did not vary, being appropriate as values: 7.53 ind $/ \mathrm{m}^{3}$ in Romanian, 6.66 ind $/ \mathrm{m}^{3}$ in Bulgarian and $6.22 \mathrm{ind} / \mathrm{m}^{3}$ in Turkish Black Sea waters.

The constant values for the average density show that $A$. patersonii population is uniform distributed, with a slight increased tendency from the Southern to the Northern analyzed area. The lack of data for a longer period does not give the opportunity to conclude if the species population tends to increase (Figure 8).

Analyzing the species distribution map, $A$. patersonii was better represented in the northern part of the Romanian marine area, where the Danube River flows in the Black Sea, indicating proper environmental conditions for this species. The species also presented high density values in the southern marine area of Bulgaria and in the central area of Turkey (Figure 8).
The highest biomass value from samples collected in the Romanian marine waters was recorded in station RO_3 $\left(2.67 \mathrm{mg} / \mathrm{m}^{3}\right)$, and the lowest $\left(0.46 \mathrm{mg} / \mathrm{m}^{3}\right)$ appeared in station RO_5 (Figure 9).

In the Bulgarian marine waters, the highest biomass value was in station BG_8 $\left(4.70 \mathrm{mg} / \mathrm{m}^{3}\right)$, and the lowest value was reached in station BG_2 (0.24 $\mathrm{mg} / \mathrm{m}^{3}$ ) (Figure 9).

In Turkish marine waters, the highest biomass value was recorded in station TR_4 $\left(3.90 \mathrm{mg} / \mathrm{m}^{3}\right)$, the lowest biomass values being in station TR_3 (0.49 $\mathrm{mg} / \mathrm{m}^{3}$ ) (Figure 9).

The average values biomass did not vary significantly. In Romanian Black Sea waters the observed value was of $1.62 \mathrm{mg} / \mathrm{m}^{3}, 2.00 \mathrm{mg} / \mathrm{m}^{3}$ in Bulgaria and $1.99 \mathrm{mg} / \mathrm{m}^{3}$ in Turkey. Although in Romania the average biomass value was lower, the average density recorded higher values, indicating a higher number of juveniles which have a lower biomass value. Therefore, $A$. patersonii population seems to be developing better in the Northern area. 


\section{Anomalocera patersonii}

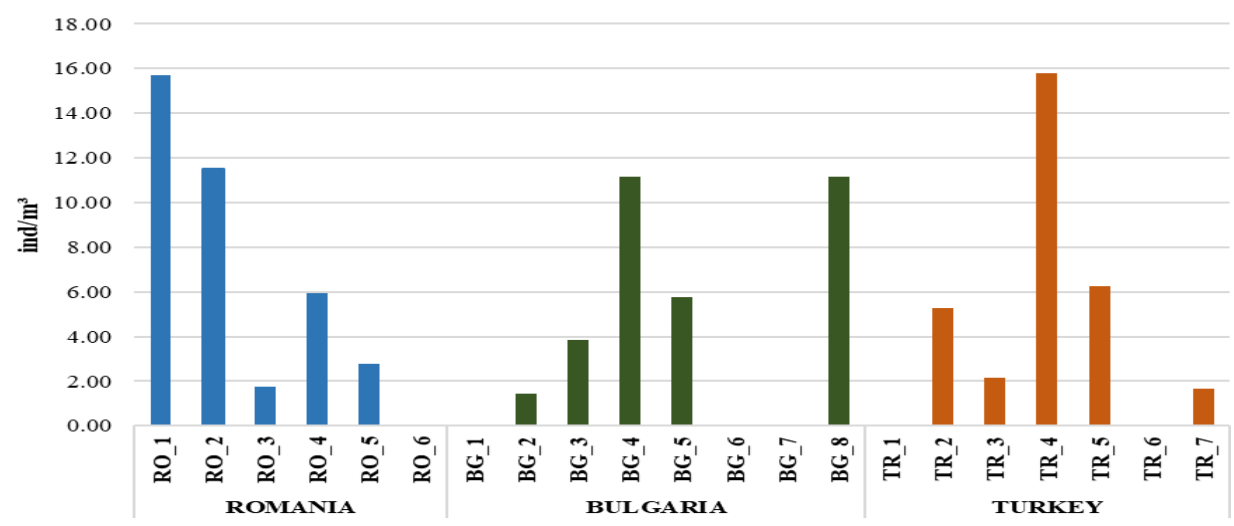

Figure 7. A. patersonii density
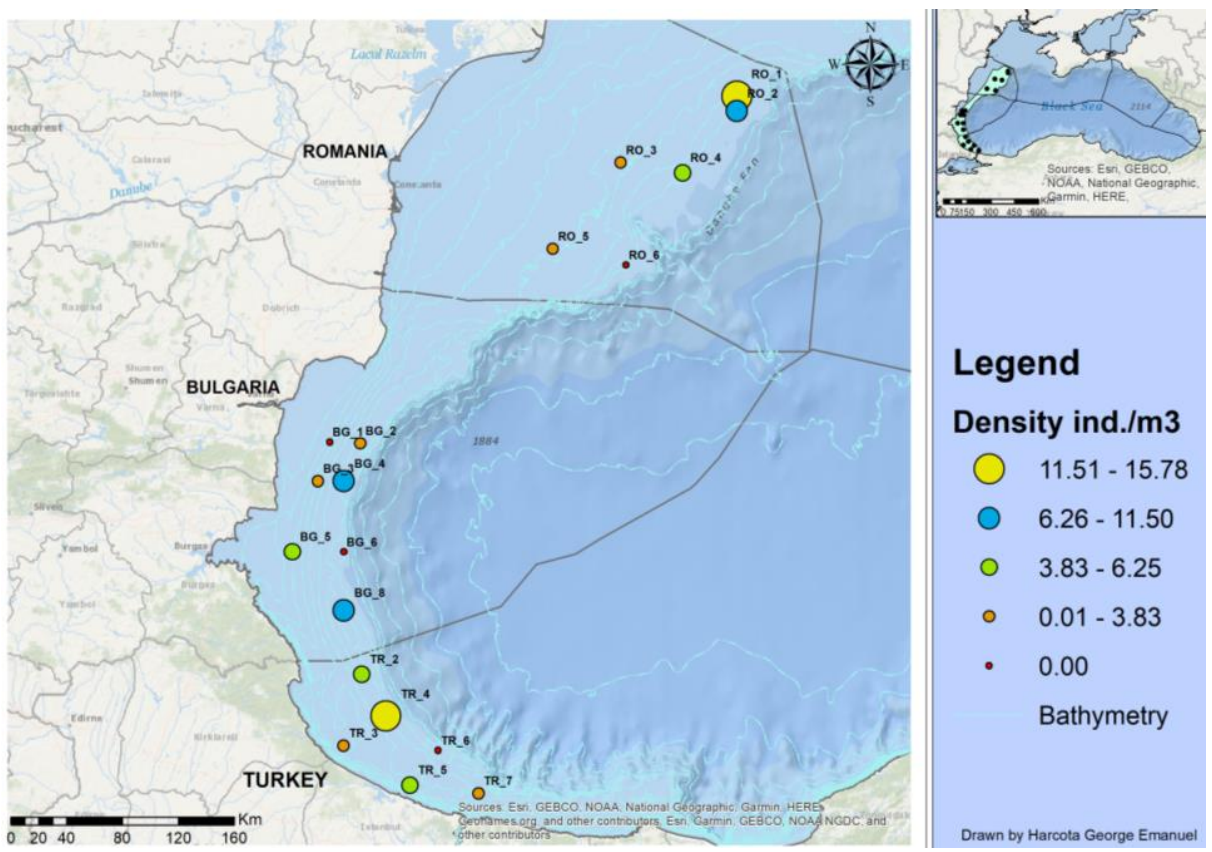

Figure 8. A. patersonii distribution map

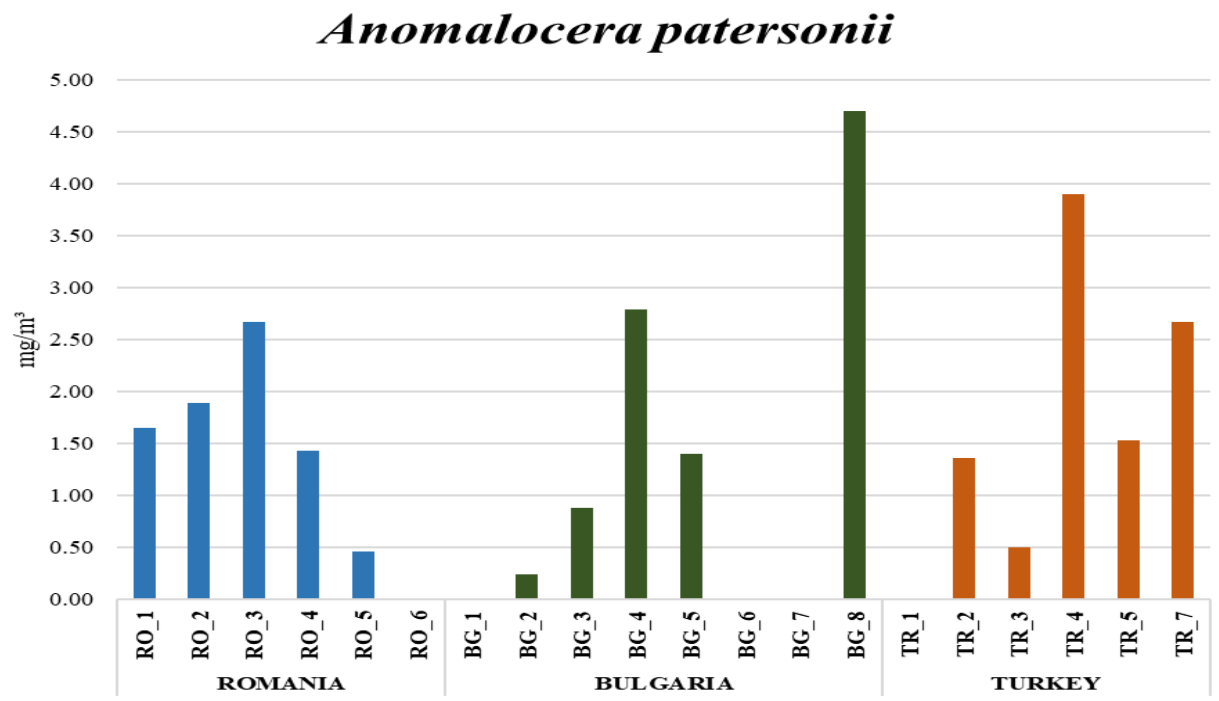

Figure 9. A. patersonii biomass 
P. mediterranea: The species recorded the highest density value in station RO_4 (47.37 ind $\left./ \mathrm{m}^{3}\right)$, station RO_1 being characterized by a low-density value $(2.14$ ind $/ \mathrm{m}^{3}$ ), (Figure $10 ; 11$ ).

In the Bulgarian marine waters, the highest density value was recorded in station BG_5 (13.42 ind $\left./ \mathrm{m}^{3}\right)$, station BG_2 reaching the lowest density value (1.42 ind $/ \mathrm{m}^{3}$ ), (Figure $10 ; 11$ ).

In the Turkish marine waters, the highest density value was in station TR_3 $\left(6.45 \mathrm{ind} / \mathrm{m}^{3}\right)$, and the lowest in station TR_7 (1.33 ind $/ \mathrm{m}^{3}$ ), (Figure. 11$)$.

In this case, the average density value varied a lot for $P$. mediterranea: $24.39 \mathrm{ind} / \mathrm{m}^{3}$, in Romania, 5.93 ind $/ \mathrm{m}^{3}$ in Bulgaria and $3.19 \mathrm{ind} / \mathrm{m}^{3}$ in Turkey. Although the samples were collected from similar depth layers, there is a very high difference regarding the density and species distribution which tends to develop better in open sea area, avoiding the coastal zones and the Danube area, where the freshwater input is very high (Zaitsev 1971).

The low salinity values recorded in Romanian Black Sea area can also be a limitation factor, this species recording a higher development in areas where the salinity values are high. In the analyzed areas, the salinity recorded values between 17.5 PSU and 18.3 PSU, being constant.

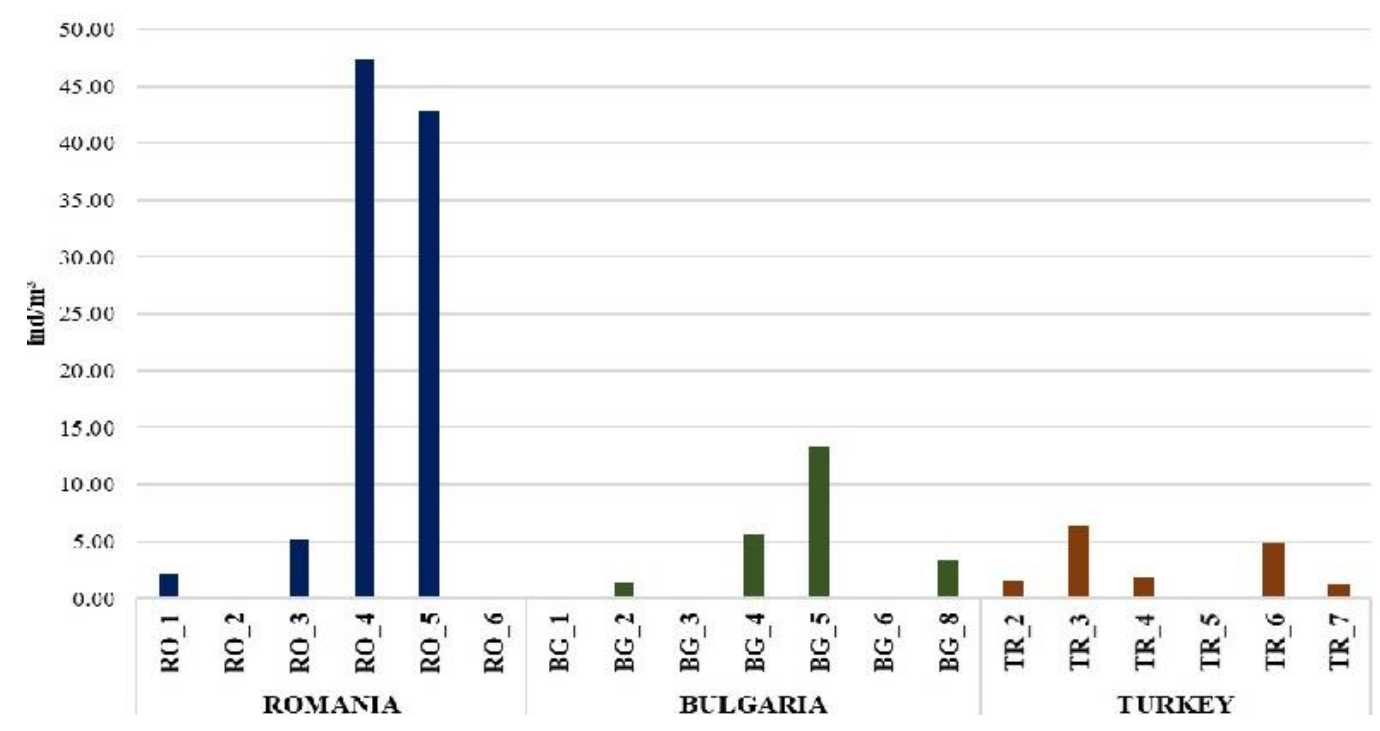

Figure 10. P. mediterranea density

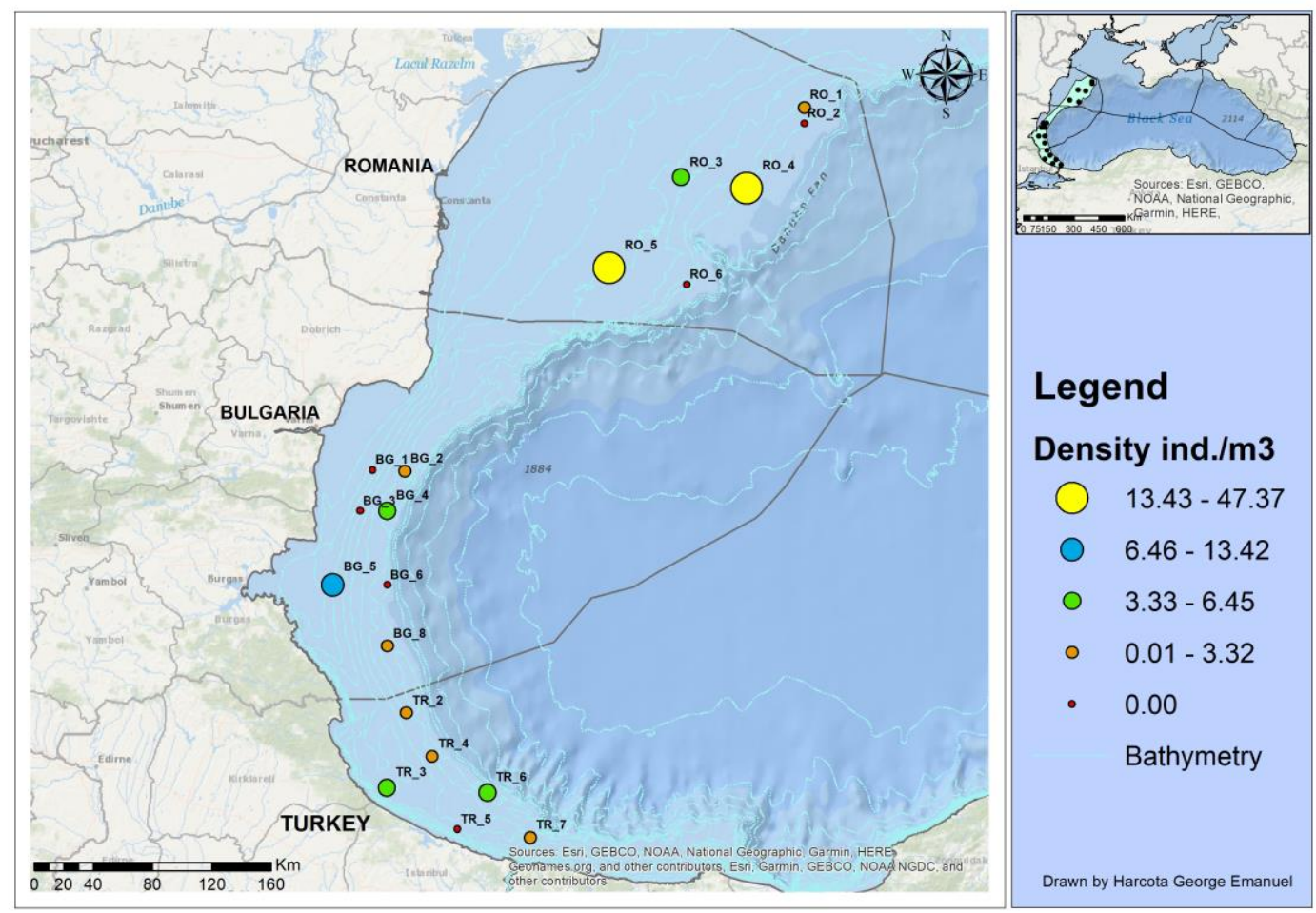

Figure 11. P. mediterranea distribution map 
Another factor that can influence the density values is the intense maritime traffic, taking into consideration that this species is found in the superficial water layer.

$P$. mediterranea distribution's map shows a high abundance only in the Romanian offshore area (Figure 11).

In the Romanian marine waters, the highest biomass value was in station RO_3 $\left(2.57 \mathrm{mg} / \mathrm{m}^{3}\right)$, and the lowest in station RO_1 $\left(0.54 \mathrm{mg} / \mathrm{m}^{3}\right)$ (Figure 12).

In the Bulgarian marine waters, station BG_8 recorded the highest biomass value $\left(4.61 \mathrm{mg} / \mathrm{m}^{3}\right)$, while the lowest value was in station BG_4 $\left(0.14 \mathrm{mg} / \mathrm{m}^{3}\right)$, (Figure 12).

In Turkish marine waters, the highest biomass value was recorded in station TR_2 $\left(1.00 \mathrm{mg} / \mathrm{m}^{3}\right)$, and the lowest in station TR_3 $\left(0.16 \mathrm{mg} / \mathrm{m}^{3}\right)$ (Figure 12$)$.

The average biomass values showed significant variations: $1.19 \mathrm{mg} / \mathrm{m}^{3}$ in Romanian, 1.93 in Bulgarian and 0.52 in Turkish Black Sea waters. In Romanian Black Sea area, the density values were again higher that the biomass, emphasizing the fact that $P$. mediterranea population was mainly represented by juveniles.

Following the analysis of the data on development stages, it resulted that the small development stages were dominant. As it can be seen in Figure 13, in the Romanian Black Sea stations, nauplii and copepodites II for both species were mainly identified, the maximum value being recorded by $P$. mediteranea with 92 nauplii in $\mathrm{RO}_{-} 4$ station.

In stations from Bulgaria, the IV ${ }^{\text {th }}$ copepodite stage for both species were common, identifying a maximum of 8 P. mediteranea individuals (copepodite IV) in station BG_8, (Figure 14).

In Turkey stations, the development stage for both species showed variations and recorded similar value, identifying 1, 2 individuals from each stage (Figure 15).

Regarding the environmental conditions from the analyzed area, the temperature had an average value of $21.49^{\circ} \mathrm{C}$, salinity recorded an average value of 17.88 $\mathrm{PSU}$, and the $\mathrm{pH}$ value was 8.68 . We cannot draw a conclusion regarding the way in which these factors influence the analyzed organisms, because the values were quite constant (Figure 16, Figure 17, Figure 18, Figure 19), but the density and biomass values varied in all stations. That is why a constant sampling is needed to be able to observe if these factors influence these organisms in some way.

\section{Discussions}

Pontellidae family (A. patersonii, $P$. mediterranea and Labidocera brunescens), showed a considerable decline, these copepods being found only in the water biotope called hyponeuston. The low frequency of pontellids attracted the attention of Black Sea researchers, therefore they were included in the Black Sea Red Book, within the IUCN "endangered" category (GEF, 1999).
Old studies on hyponeustone write that on 11 September 1963 a sample taken from the Danube hydrofront, ( $0.5 \mathrm{~m}$ wide and $2 \mathrm{~m}$ long) contained the following neustons: adult $P$. mediterranea $(117,760$ individuals), (Zaitsev 1997), which indicated a clean and favorable ecosystem for hyponeustonic organisms. During 1992-1995 in the northeast and northwest of the Black Sea the number of Pontella did not increase significantly (Zaitsev et al., 1997).

A sharp decline in the copepod's population numbers started since the 1970s, and a reduction of 50$70 \%$ over the last 10 years was recorded. Information from the National Report of the Russian Federation in 1960-1990 period shows how neustonic species are declining.

The average number of organisms in the 1967 1975 period was of 674 individuals, in the 1980-1985 period decreased reaching 136 individuals, in 1989-1991 the number decreased drastically to 6 individuals, and only in the 1992-1993 period an insignificant increase of 26 individuals was observed (Zaitsev et al., 1997). Pollution of the microlayer water surface and eutrophication triggering bottom hypoxia are the main threats for the two species (GEF, 1999).

The monitoring expeditions carried out by the National Institute for Marine Research and Development "Grigore Antipa" Constanța, in 1994 revealed the reappearance of these organisms in all development stages (nauplii, juveniles and adults). According to bibliographic data, the species were present in the analyzed samples as follows: $A$. patersonii was first observed in September 1998, in the upper layer of Mila 9 station. In the samples collected between 2002 and 2003, A. patersonii was identified together with individuals of $P$. mediterranea species, in July, September and October, in samples collected from Constanța marine area and from Danube Mouths. Although quantitatively the presence of these species is still insignificant, it is important for marine biodiversity and for establishing the ecological status of the marine environment (Moldoveanu \& Timofte, F 2004).

In 2019, research on organisms found in the hyponeuston was started again. From the qualitative and quantitative point of view, two hyponeustonic species were identified: $A$. patersonii and $P$. mediterranea. The samples analyzed in 2019 showed significant densities of these species, being found in different development stages, from nauplii to copepodites but also as adults and having a representative distribution on the entire analyzed surface (Figure $8 ; 11$ ).

In the future we aim to take as many neuston samples as possible and see their evolution in terms of quantity, but also their spatial distribution. That is why we will focus on the number of nauplii and juveniles that appeared and the areas where they have high densities. The fact that they appear more and more frequently in samples suggests that the ecosystem is beginning to rehabilitate. 


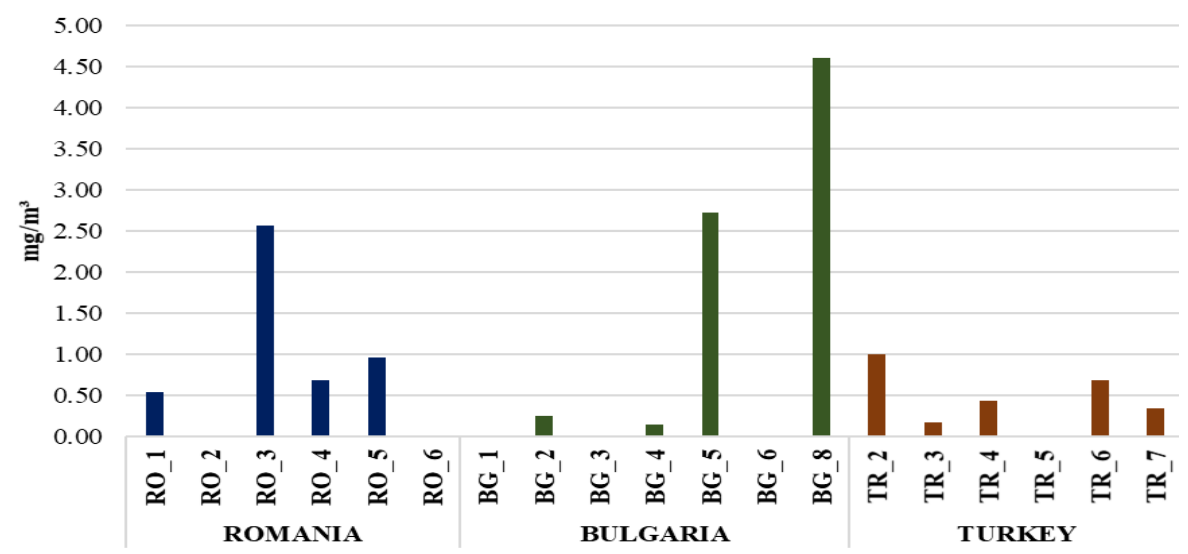

Figure 12. P. mediterranea biomass

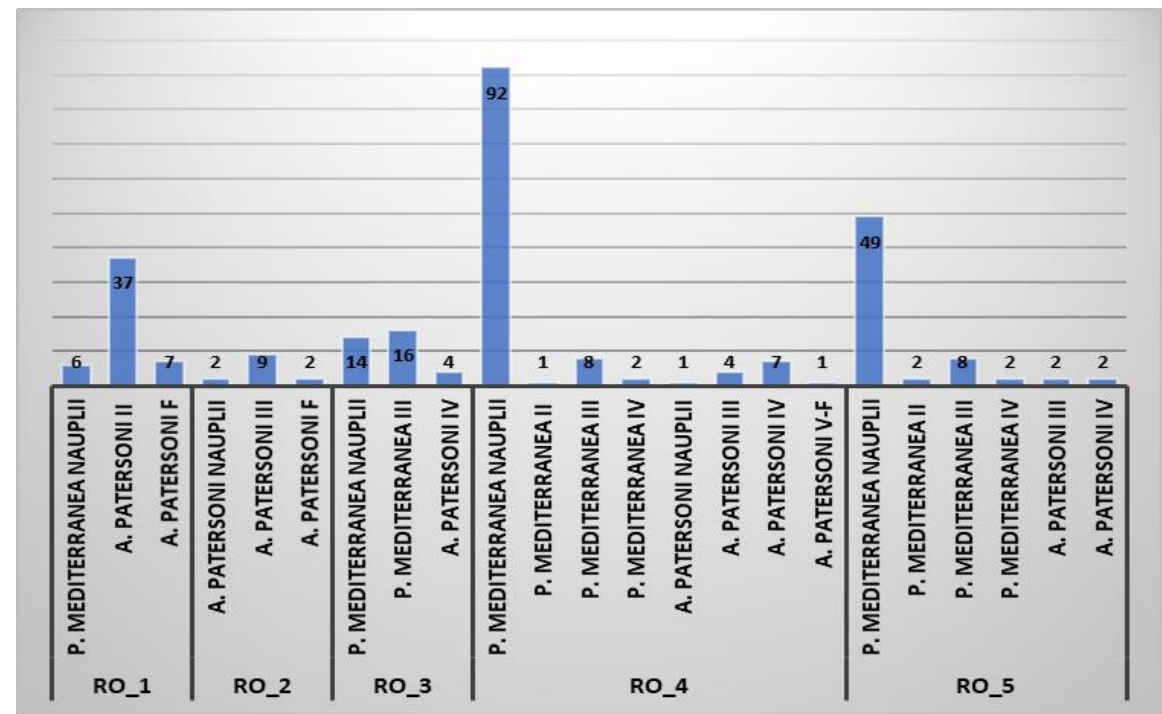

Figure 13. The development stages of pontellides in Romania

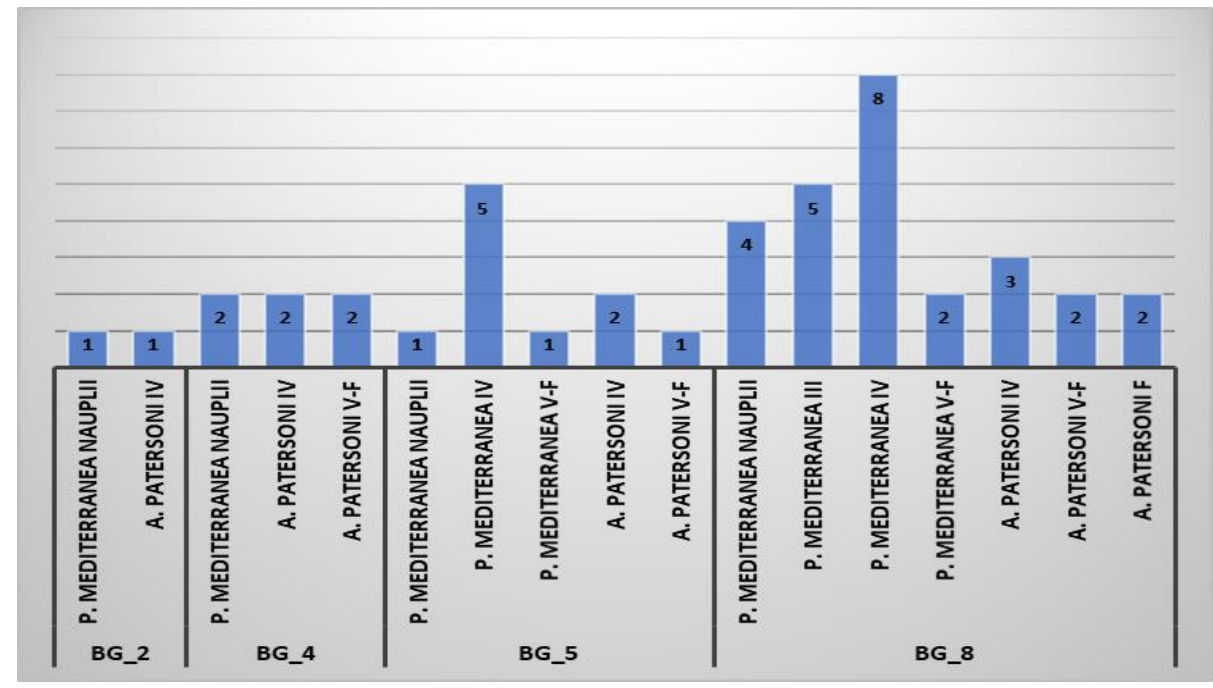

Figure 14. The development stages of pontellides in Bulgaria 


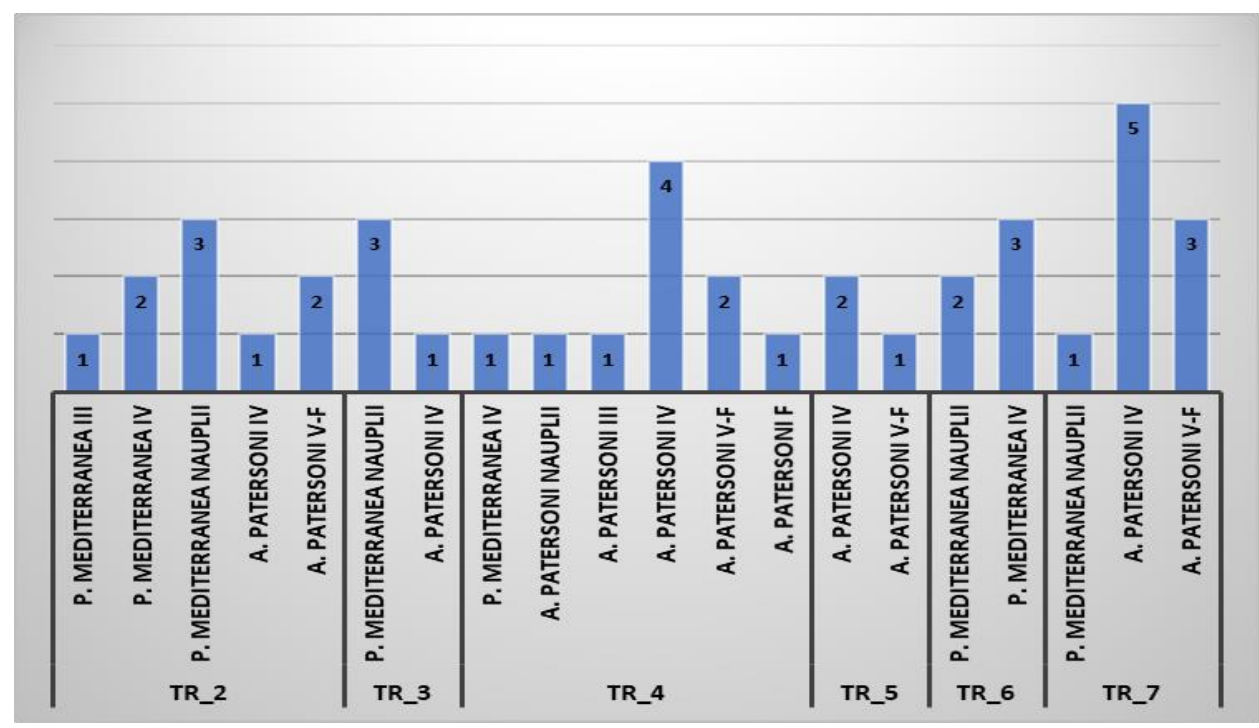

Figure 15. The development stages of pontellides in Turkey

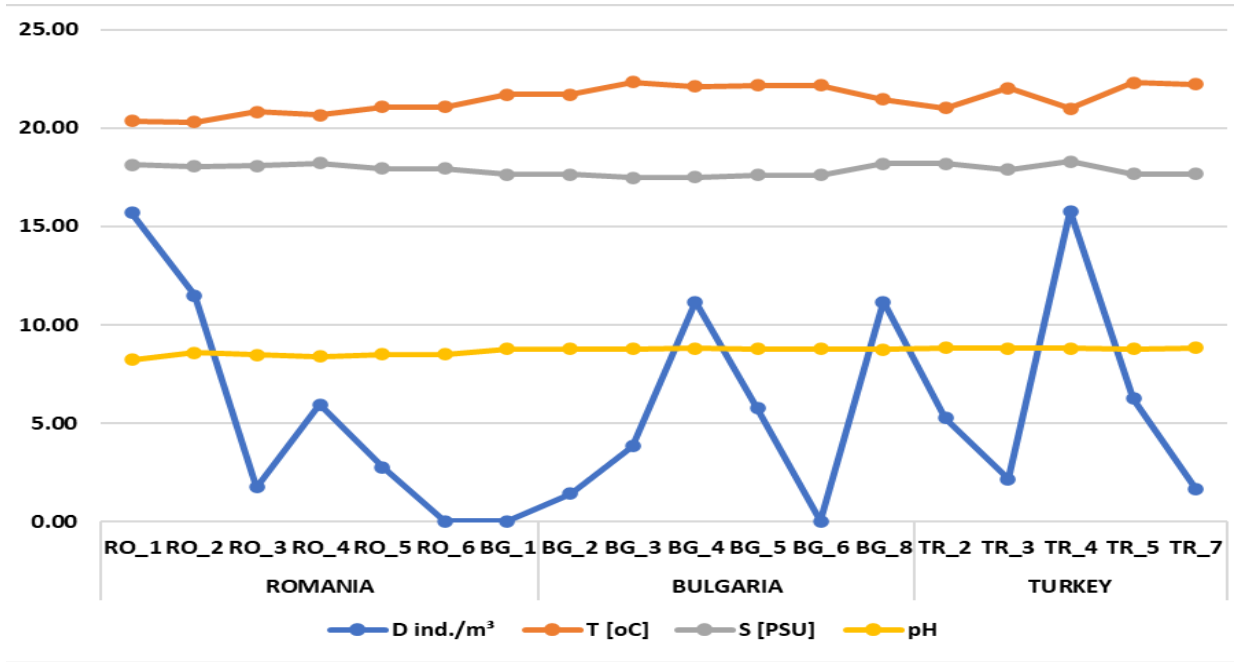

Figure 16. A. patersonii Density. Environmental conditions

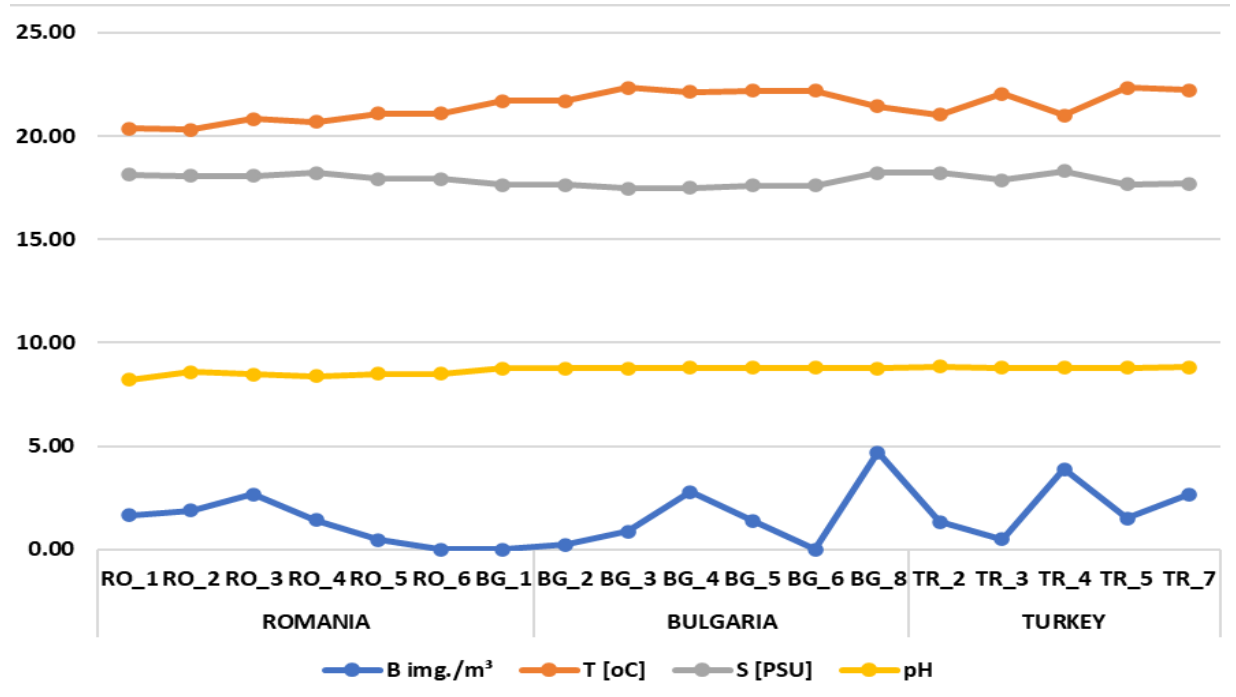

Figure 17. A. pantersonii Biomass. Environmental conditions 


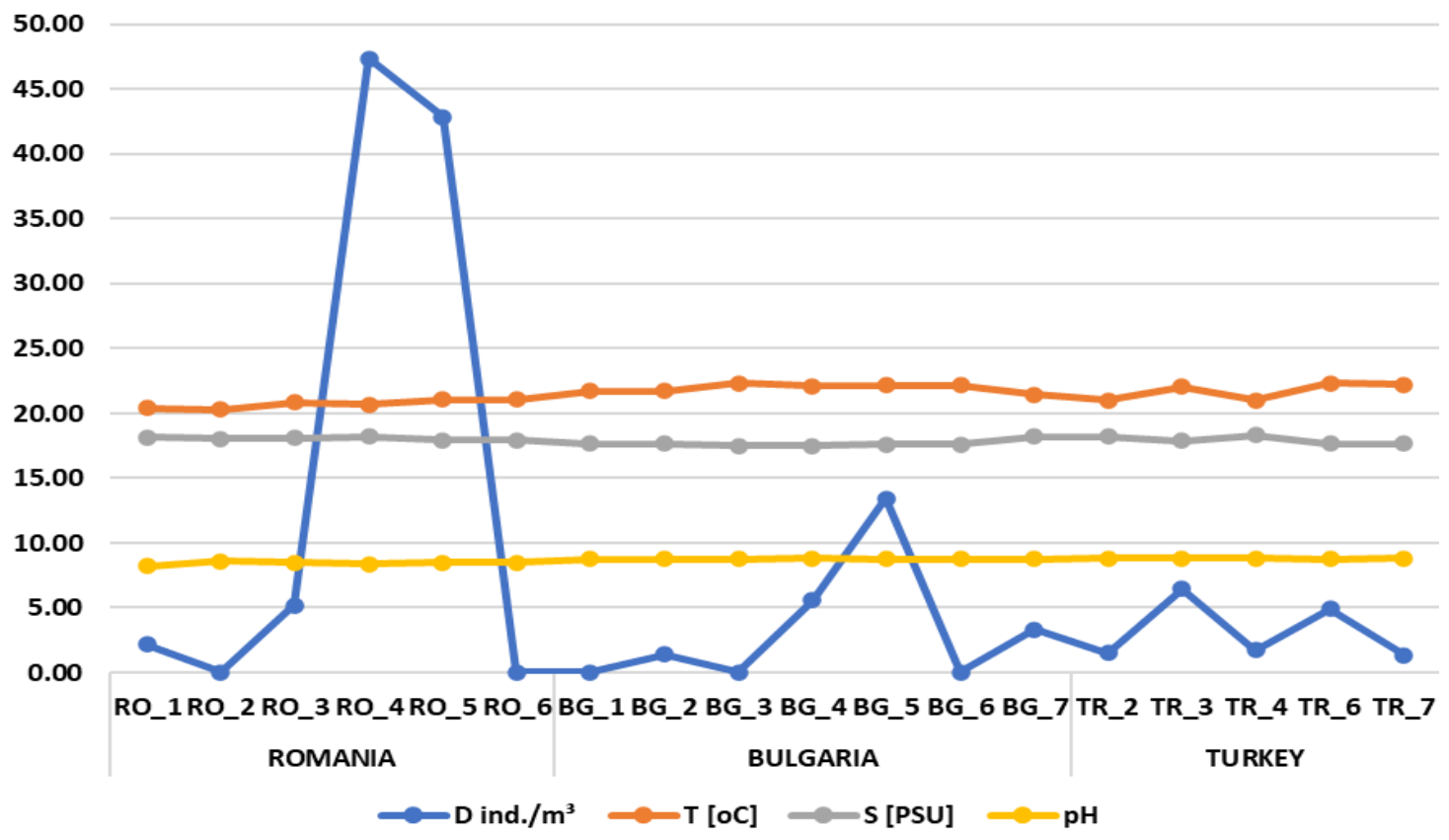

Figure 18. P. mediterranea Density. Environmental conditions

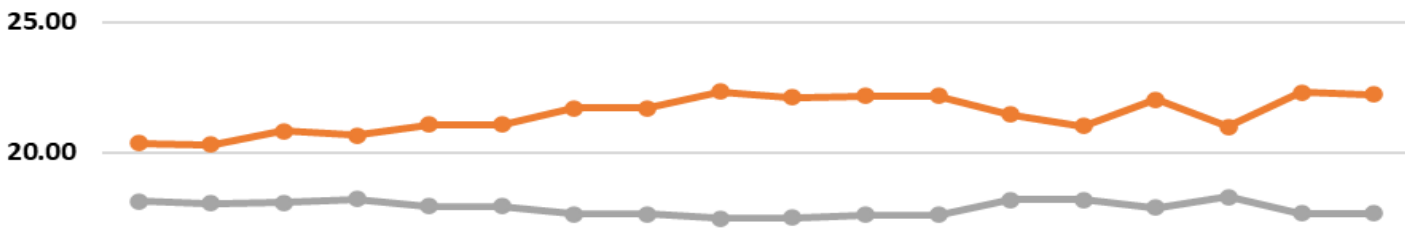

15.00

10.00
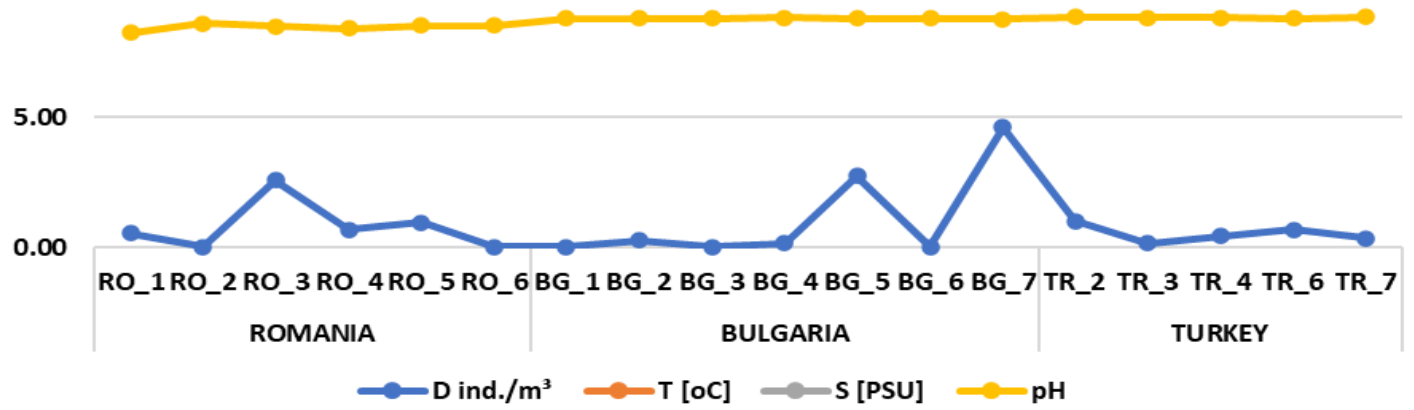

Figure 19. P. mediterranea Biomass. Environmental conditions

\section{Conclusions}

The aim of this paper is to emphasize that the two analyzed species are not extinct and that they even show an increase in the analyzed area.

A. patersonii was more abundant in the northern part of the Romanian marine area, the southern marine area of Bulgaria and in the central area of Turkey.

$A$. patersonii and $P$. mediterranea recorded higher density values in the open sea area, where factors that can limit the population's development are lower than in the coastal zones.

$P$. mediterranea recorded a high abundance in the Romanian Black Sea area and biomass recorded minimum values in samples collected from the Bulgarian area, in stations BG_4 $\left(0.14 \mathrm{mg} / \mathrm{m}^{3}\right)$.

Analyzing the data of the two pontellid species, they are found only in areas which are critical to the survival of certain species, representing a limited habitat area with a low density of these organisms. 


\section{Ethical Statement}

This material is the authors' own original work, which has not been previously published elsewhere.

The paper is not currently being considered for publication elsewhere.

The paper reflects the authors' own research and analysis in a truthful and complete manner.

The paper properly credits the meaningful contributions of co-authors and co-researchers.

The results are appropriately placed in the context of prior and existing research.

All sources used are properly disclosed (correct citation). Literally copying of text must be indicated as such by using quotation marks and giving proper reference.

All authors have been personally and actively involved in substantial work leading to the paper and will take public responsibility for its content.

I agree with the above statements and declare that this submission follows the policies as outlined in the Guide for Authors and in the Ethical Statement.

\section{Funding Information}

The study has been supported by the ANEMONE project "Assessing the vulnerability of the Black Sea marine ecosystem to human pressures", funded by the EU under ENI CBC Joint Operational Programme "Black Sea Basin 2014-2020", grant contract 83530/20.07.2018.

\section{Author Contribution}

George-Emanuel HARCOTĂ and Aurelia TOTOIU analyzed the collected sampling and wrote the first draft of the manuscript. Elena BISINICU corrected the draft and built the final version of the manuscript. Cristina TABARCEA, Laura BOICENCO, Florin TIMOFTE contributed to manuscript revision, and read and approved the submitted version.

\section{Conflict of Interest}

The authors whose names are listed immediately below certify that they have NO affiliations with or involvement in any organization or entity with any financial interest (such as honoraria; educational grants; participation in speakers' bureaus; membership, employment, consultancies, stock ownership, or other equity interest; and expert testimony or patentlicensing arrangements), or non-financial interest (such as personal or professional relationships, affiliations, knowledge or beliefs) in the subject matter or materials discussed in this manuscript.

\section{Acknowledgements}

This study has been supported by the ANEMONE project (funded by the EU under ENI CBC Black Sea basin Programme 2014-2020, grant contract 83530)

\section{References}

Alexandrov, B., \& Arashkevich, E., \& Gubanova, A., \& Korshenko, A. (2014). Black Sea Monitoring Guidelines Mesozooplankton. 31. http://emblasproject.org/wpcontent/uploads/2017/01/MesozooplanktonFinalJuly2015-PA3-f.pdf

Doyle, MJ. (1992). Neustonic ichthyoplankton in the northern region of the California current system. CalCOFI rep. 33, 141-161. http://calcofi.org/publications/calcofireports/v33/Vol_ 33_Doyle.pdf

GEF (1999). Global Environment Facility. United Nations Development Programme (UNDP). Black Sea Red Data Book, 414pp.

Hardy, JT. (1997). Biological effects of chemicals in the seasurface microlayer. In: Liss PS, Druce RA (eds) The sea surface and global change. Cambridge University Press, Cambridge, 339-370.

Holdway, P, \& Maddock, L. (1983). A comparative survey of neuston: geographical and temporal distribution patterns. Marine Biology, 76, 263-270. https://doi.org/10.1007/BF00393027

Marshall, H.G., \& Burchardi, L. (2005). Neuston: its definition with a historical review regarding its concept and community structure. Arch Hydrobio, 164, 429-448 https://doi.org/10.1127/0003-9136/2005/0164-0429

Moldoveanu, M., \& Timofte, F. (2004). Signs of marine ecosystem rehabilitation along the Romanian Black Sea littoral identified by zooplankton indicator after 1994, Recherches Marines, 35, 87-108.

Petipa, T. S. (1957). On average weight of the main zooplankton forms in the Black Sea.Proc Sevastopol Biol St 9:39-57 (in Russian).

Rawlinson, KA., \& Davenport, J., \& Bames, DKA. (2005). Temporal variation in diversity and community structure of a semi-isolated neuston community. Biology and Environment, 105B (2), 107-122. http://www.jstor.org/stable/20500241

Ré, Pedro. (2005). Ecologia Marinha. Faculdade de Ciĺncias da Universidade de Lisboa, University of Lisboa, 64.

Tully, O, \& O'Ceidigh, P. (1989). The ichthyoneuston of Galway Bay (west of Ireland). II. Food of postlarval and juvenile neustonic and pseudoneustonic fish. Marine Ecology, 51, 301-310. http://dx.doi.org/10.3354/meps051301

Wurl O, \& Obbard, JP. (2004). A review of pollutants in the seasurface microlayer (SML): a unique habitat for marine organisms. Marine Pollution Bulletin, 48, 1016-1030. https://doi.org/10.1016/j.marpolbul.2004.03.016

Zaitsev, Yu. P. (1968). La neustonologie marine: objet, methodes, realisations principales et problemes. Pelagos. Bull. Institut of Oceanography., Alger., 8, 1-48.

Zaitsev, Yu. P. (1970). Marine neustonology, 207pp., Hydrobiology, 58, 596. 
https://doi.org/10.1002/iroh.19730580414

Zaitsev, Yu. P. (1971). Marine neustbnology (Original title: Morskaya Neistonologiya)

Marine Neustonology, Academy of Sciences of the Ukrainian SSR, Kiev $401 \mathrm{p}$.

Zaitsev, Yu. P. (1990). Some possible consequences of forecasting climate changes and increases in ocean levels for the Black Sea area. Odessa, Dep. VINITI,777B90,1-17.

Zaitsev, Yu. P., \& Mamaev V. (1997), Marine Biological Diversity in the Black Sea A Study of Change and Decline. Colonial Waterbirds, 21 (1), 208p https://doi.org/10.2307/1521749

Zaitsev, Yu. P., \& Mamaev V. (1997). The book Marine Biological Diversity in the Black Sea. A Study of Change and Decline. United Nations Publications (New York)

Zernov, S. A. (1934). General Hydrobiology (in Russian). Moskow, Leningrad: Biomedgiz, 504 pp. https://www.hydrobios.de/images/datasheets/438\%20 110_\%20Mechanical\%20Flow\%20Meter.pdf 